\title{
O ENSINO-APRENDIZAGEM DA ORALIDADE FORMAL E O APREÇO À TOLERÂNCIA E À DIVERSIDADE DE PONTOS DE VISTA
}

\author{
THE TEACHING-LEARNING OF FORMAL ORALITY AND THE \\ APPRECIATION OF TOLERANCE AND DIVERSITY OF POINTS OF \\ VIEW
}

\begin{abstract}
Sirley Siqueira ${ }^{1}$
RESUMO: Este artigo tem por objetivo reiterar a importância de se trabalhar gêneros textuais típicos da oralidade no contexto da Educação Básica. Assumindo uma concepção interacional da linguagem, pretende também apresentar algumas respostas para os seguintes questionamentos: "Qual é a relevância do trabalho com a oralidade em sala de aula?" e "Por que o gênero textual debate regrado pode ser uma opção para a aquisição de usos formais da fala em público e para a formação cidadã pautada no respeito ao outro?”. Apresenta ainda um exemplo de prática pedagógica voltada para a aquisição da oralidade formal, por meio do trabalho com o gênero debate regrado, desenvolvida com alunos do Ensino Médio. Tal atividade demonstrou ser um dos caminhos possíveis para o exercício da escuta atenta ao que o interlocutor tem a dizer, ao mesmo tempo em que promove o desenvolvimento da expressão oral formal requerida em diversas práticas sociais.
\end{abstract}

PALAVRAS-CHAVE: Oralidade. Ensino. Debate regrado.

ABSTRACT: This article aims to reiterate the importance of working with textual genres that are typical of orality in the environment of Basic Education. Assuming an interactional conception of language, it also intends to present some answers to the following questions: "What is the relevance of working with orality in the classroom?" and "Why the textual genre regulated debate can be an option for acquisition of formal uses of speech in public and for civic educational based on respect for the other?". It also presents an example of pedagogical practice aimed at the acquisition of formal orality, through work with the regulated debate genre, developed with high school students. This activity proved to be one of the possible paths for the exercise of attentive listening to what the interlocutor has to say, while promoting the development of the formal oral expression required in many social practices.

KEYWORDS: Orality. Teaching. Ruled debate

\section{Apresentação}

Nos últimos anos, o aprofundamento de posições ideológicas distintas tem reiterado a importância de se empreender um movimento contrário, no qual vozes discordantes possam ser

\footnotetext{
${ }^{1}$ Doutora em Estudos da Linguagem (UFF). Professora do Ensino Básico Técnico e Tecnológico do Colégio Pedro II. Coordenadora do Laboratório de Estudo de Práticas Educativas em Língua Portuguesa e Literatura (LEPELL CPII). E-mail: sirley.ribeirosiqueira@gmail.com
} 


\section{PERcursos Linguísticos • Vitória (ES) •v. 11 •n. 29 • 2021 • ISSN: 2236-2592 • Dossiê temático $\bullet O$ texto na pesquisa e no ensino: conhecimentos, práticas e desafios na contemporaneidade •}

ouvidas e estabelecido um diálogo saudável. Essa interlocução atenta e respeitosa ao que o outro tem a dizer, marco das sociedades civilizadas, precisa ser incentivada, assim como deve ser ampliada a capacidade de expor os próprios argumentos e defendê-los. Nesse sentido, precisa ser um compromisso de toda comunidade escolar a busca por relações mais harmoniosas, nas quais seja possível repelir discursos de ódio ou que atentem contra a democracia, a fim de contribuir para uma formação cidadã atenta ao bem-estar de toda coletividade.

A partir da década de 1980, período que coincide com a redemocratização brasileira, houve uma intensificação de trabalhos ligados ao ensino da língua materna como os de Marcuschi (1986), Koch (1996), Castilho \& Basílio (1996), Castilho (1998), Almeida (2006) e Geraldi (2006). Questões norteadoras desse período diziam respeito, principalmente, ao "Para que se ensina a Língua Portuguesa?". Essas inquietações ganharam relevo e culminaram na publicação dos Parâmetros Curriculares Nacionais (PCN) (BRASIL, 1997), documento que trouxe ainda maior visibilidade para a imprescindível mudança nas aulas de Português, as quais se pautavam, muitas vezes, quase exclusivamente no ensino de nomenclatura gramatical ou em práticas ligadas ao trabalho com o texto escrito. A partir desses referenciais nacionais, sobretudo, houve um crescente destaque para o ensino da linguagem e de gêneros orais (formais públicos) e a valorização dos contextos de uso e de circulação.

Em relação ao ensino da oralidade, por exemplo, encontramos a seguinte passagem no documento:

\footnotetext{
Ensinar língua oral deve significar para a escola possibilitar acesso a usos da linguagem mais formalizados e convencionais, que exijam controle mais consciente e voluntário da enunciação, tendo em vista a importância que o domínio da palavra pública tem no exercício da cidadania. Ensinar língua oral não significa trabalhar a capacidade de falar em geral. Significa desenvolver o domínio dos gêneros que apoiam a aprendizagem escolar de Língua Portuguesa e de outras áreas (exposição, relatório de experiência, entrevista, debate etc.) e, também, os gêneros da vida pública no sentido mais amplo do termo (debate, teatro, palestra, entrevista etc.). Já que os alunos têm menos acesso a esses gêneros nos usos espontâneos da linguagem oral, é fundamental desenvolver, na escola, uma série de atividades de escuta orientada, que possibilitem a eles construir, progressivamente, modelos apropriados ao uso do oral nas circunstâncias previstas. (BRASIL, 1997, p.67).
}

Mais recentemente, outro documento oficial, a Base Nacional Curricular Comum, doravante BNCC (BRASIL, 2018), estabelece as seguintes práticas de linguagem para o Ensino Fundamental e Médio: leitura, produção de textos, oralidade (escuta e produção oral) e análise linguística e semiótica (BRASIL, 2018, p.492). Trabalhar com todos esses eixos, de fato, é um 


\section{PERcursos Linguísticos • Vitória (ES) •v. 11 •n. 29 • 2021 • ISSN: 2236-2592 • Dossiê temático $\bullet O$ texto na pesquisa e no ensino: conhecimentos, práticas e desafios na contemporaneidade •}

desafio, especialmente em um contexto no qual se percebe uma drástica redução dos investimentos em educação - o que impacta não só a diminuição e precarização de recursos pedagógicos, mas, sobretudo, a formação inicial e continuada dos professores. Entretanto, mesmo em meio a tantos obstáculos, é imperioso que práticas sedimentadas no passado possam dar lugar a ações baseadas em referenciais teórico-metodológicos consistentes, os quais apoiem um trabalho no qual seja preconizado o uso linguístico.

Koch (2002, p. 17) afirma que, numa concepção interacional da língua, na qual os sujeitos são vistos como atores/ construtores sociais, "o texto passa a ser considerado o próprio lugar de interação e os interlocutores, como sujeitos ativos que dialogicamente - nele constroem e são construídos". Dolz e Schneuwly, também inspirados por uma concepção interacionista, afirmam que é preciso dar prioridade ao funcionamento comunicativo dos alunos. Isso deve ser feito com o intuito de:

- prepará-los para dominar a língua em situações variadas, fornecendo-lhes instrumentos eficazes:

- desenvolver nos alunos uma relação com o comportamento discursivo consciente e voluntária, favorecendo estratégias de autorregulação;

- ajudá-los a construir uma representação das atividades de escrita e de fala em situações complexas, como produto de um trabalho e de uma lenta elaboração. (DOLZ; SCHNEUWLY, p.42, 2004,).

Subsidiar nossas práticas diárias de sala de aula nessa concepção de texto e de sujeitos é um importante passo para refletirmos sobre o que consideramos mais relevante nas aulas de Língua Portuguesa, tendo em mente nosso compromisso como educadores, os quais desejam contribuir para a formação de cidadãos pensantes e que não se calam frente a injustiças. Portanto, de modo a reiterar a importância de tal temática, este artigo tem como objetivo contribuir para a expansão das discussões que envolvem o ensino da oralidade no âmbito escolar (RAMOS，2002; GOMES-SANTOS，2009; LEAL; GOIS，2012; NONATO， 2018), especialmente por meio da apresentação de uma prática pedagógica baseada no trabalho com o gênero debate regrado.

Ao longo deste texto, procuraremos responder a duas perguntas "Qual é a relevância do trabalho com a oralidade em sala de aula?" e "Por que o gênero textual debate regrado pode ser uma opção para a aquisição de usos formais da fala em público e para a formação cidadã pautada no respeito ao outro?". Além disso, também apresentaremos um exemplo de uma prática de ensino, desenvolvida com alunos do Ensino Médio do Colégio Pedro II, uma escola 


\section{PERcursos Linguísticos • Vitória (ES) •v. 11 •n. 29 • 2021 • ISSN: 2236-2592 • Dossiê temático $\bullet O$ texto na pesquisa e no ensino: conhecimentos, práticas e desafios na contemporaneidade •}

pública federal localizada no município do Rio de Janeiro, cujo principal eixo de ação foi a criação de uma Sociedade de Debates, sobre a qual discorreremos adiante.

\section{Qual é a relevância do trabalho com a oralidade em sala de aula?}

O meio acadêmico há muito tem defendido a necessidade de se fazer da oralidade um objeto de ensino (CASTILHO, 1998; SCHNEUWLY; DOLZ, 2004; FÁVERO et al, 2005; MAGALHÃES, 2006). Entretanto, ainda perdura, para muitos, o entendimento de que o ensino da língua escrita deve ser priorizado, uma vez que a fala seria uma habilidade adquirida espontaneamente, dado o fato de que as crianças já chegam à escola sabendo falar. Para desconstruir essa ideia equivocada, a de que as aulas de Língua Portuguesa devem ter como foco exclusivamente o texto escrito, é preciso rever as metas a que se propõe alcançar: se, de fato, almeja-se contribuir para a ampliação das competências de ouvir, falar, ler e escrever, o ensino da oralidade não pode ser visto como secundário ou mesmo dispensável.

De acordo com Schneuwly, é preciso assumir uma concepção mais rica e complexa do oral e uma relação mais dialética entre oral e escrita. Segundo o autor,

\footnotetext{
Não existe 'o oral', mas 'os orais' em múltiplas formas que, por outro lado, entram em relação com os escritos, de maneiras muito diversas: podem se aproximar da escrita e mesmo dela depender - como é o caso da exposição oral ou, ainda mais, do teatro e da leitura para os outros -, como também podem estar mais distanciados como nos debates ou, é claro, na conversação cotidiana. Não existe uma essência mítica do oral que permitiria fundir sua didática, mas práticas de linguagem muito diferenciadas, que se dão, prioritariamente, pelo uso da palavra (falada), mas também por meio da escrita, e são essas práticas que podem se tornar objetos de um trabalho escolar. (SCHNEUWLY, p.114, 2004).
}

Tal como há uma variedade de gêneros escritos, dos mais formais aos extremamente informais, há também uma gama de gêneros orais, os quais se distinguem pelo contexto situacional e pelas formas convencionais ligadas aos mesmos. Nesse sentido, é preciso perceber que, embora os alunos já dominem o oral cotidiano, é necessário empreender ações para que eles possam alcançar outras formas de produção, as quais exijam maior preparo, uma vez que estariam inseridas em contextos públicos mais formais.

Ferrarezi, acerca das expectativas de aprendizagem relacionadas ao ensino da oralidade, afirma que é preciso que a escola busque desenvolver nos alunos as habilidades de: 


\section{PERcursos Linguísticos • Vitória (ES) •v. 11 •n. 29 • 2021 • ISSN: 2236-2592 • Dossiê temático $\bullet O$ texto na pesquisa e no ensino: conhecimentos, práticas e desafios na contemporaneidade •}

- organizar o conteúdo a ser expresso;

- demonstrar princípios de cortesia e ${ }^{2}$ polidez ao falar;

- demonstrar desenvoltura e desinibição pessoal e, em certas situações específicas, boa dose de intrepidez;

- distinguir o tipo de público que ouve a fala produzida, proporcionando perfeita adequação entre o padrão produzido e as expectativas dos ouvintes;

- educar a voz, incluindo a impostação e a melodia expressiva;

- pronunciar adequada e claramente as palavras utilizadas;

- utilizar um vocabulário múltiplo, adequado às necessidades expressivas identificadas;

- construir sentenças adequadas àquilo que se quer expressar, no padrão que escolheu como mais adequado em cada situação real de vida;

- reconhecer a importância e as consequências da própria fala - desenvolver a fala responsável;

- integrar o falar com o ouvir, o ler e o escrever. (FERRAREZI, p. 73, 2014).

Todas essas demandas, de fato, reiteram a importância de se fazer da oralidade um objeto de ensino. Desse modo, a escola precisa assumir a tarefa de levar os alunos a irem além do domínio do oral distenso e buscar meios para que o ensino da oralidade formal tenha efetivamente seu espaço no ambiente escolar. É necessário, portanto, propor atividades que evidenciem aos alunos que há gêneros da oralidade que impõem controle consciente e voluntário do próprio comportamento e que exigem preparação. Essa mesma defesa é compartilhada por Costa-Maciel e Bilro, quando afirmam que:

Focar o ensino da oralidade no estudo desses gêneros [formais] possibilita aos indivíduos desenvolver competências que, em geral, não são apreendidas no cotidiano, por não fazerem parte das instâncias privadas de produção e por demandarem um maior grau de planejamento no uso da fala pública. (COSTAMACIEL \& BILRO, 2018, p.2).

Concordamos com Carvalho e Ferrarezi (2018, p.32) para quem “(...) as competências mais complexas da oralidade demandam ensino formal e sistemático: não são um 'dom' que qualquer um vai receber magicamente quando for mais velho". Assim, fica evidente a necessidade de planejamento e organização curricular a fim de que haja espaço para atividades voltadas para a ampliação da competência de falar em público, tendo em vista o contexto situacional, o assunto, o interlocutor e ainda a necessidade de se expressar de maneira respeitosa e atenta.

\footnotetext{
${ }^{2}$ Compartilhamos o mesmo entendimento de polidez, presente em Brown e Levinson (1987), o qual se apoia em duas noções: (a) a de que a comunicação é uma atividade racional que tem alguma finalidade, e (b) a noção de que cada um deseja proteger a sua face ou imagem pública. Essa imagem pública (face) diz respeito a dois tipos de desejo: (a) o desejo de autoafirmação, de não se submeter a condições, ter liberdade de ação: face negativa, e (b) o de ser aprovado, aceito, apreciado pelo(s) parceiro(s) da atividade comunicativa: face positiva.
} 


\section{PERcursos Linguísticos • Vitória (ES) •v. $11 \bullet$ •n. 29 • 2021 • ISSN: 2236-2592 • Dossiê temático $\bullet O$ texto na pesquisa e no ensino: conhecimentos, práticas e desafios na contemporaneidade •}

\section{Por que o gênero textual debate regrado pode ser uma opção para a aquisição de usos formais da fala em público e para a formação cidadã pautada no respeito ao outro?}

Há diversos gêneros típicos da oralidade que podem e devem também ser privilegiados em sala de aula, na Educação Básica, com o intuito de se trabalhar a oralidade formal. Alguns desses gêneros farão parte, inclusive, do cotidiano dos alunos que ascenderem a patamares mais elevados de ensino, como é o caso do seminário ou da exposição oral; ou ainda da entrevista, a qual fará parte da vida de muitos jovens e adultos, ao buscarem uma colocação no mercado de trabalho. Entretanto, há algumas potencialidades do debate regrado, as quais merecem ser mencionadas, uma vez que esse gênero:

a) fomenta o amadurecimento da escuta do outro, já que se trata de um gênero no qual há uma alternância imediata dos turnos de fala entre os interlocutores;

b) promove a construção coletiva de conhecimento e opiniões e, consequentemente, o respeito pelo outro;

c) desenvolve habilidades linguísticas como a capacidade de fazer referência ao discurso alheio e refutá-lo;

d) amplia o escopo do trabalho com o ensino de $\operatorname{argumentação~}^{3}$, muitas vezes, restrito ao texto escrito em contextos escolares.

É preciso reiterar, inclusive, a importância de se trabalhar com gêneros do argumentar em toda a Educação Básica e, sobretudo, no Ensino Médio. Isso porque é por meio deles que nos constituímos como sujeitos pensantes, capazes de entender os discursos alheios, as teses subjacentes e também podemos veicular nosso próprio posicionamento. É ainda através do trabalho com a argumentação que se exercita a escuta e o respeito ao nosso semelhante e que

\footnotetext{
${ }^{3}$ Adotamos a concepção de argumentação presente em Charaudeau, 2004, p.37, 44, segundo a qual ela se refere a uma prática social na qual o sujeito que quer argumentar se encontra restringido pelos dados da situação comunicativa e, ao mesmo tempo, livre para jogar com essas restrições, sendo possível realizar seu próprio projeto de fala e trabalhar estratégias. Com relação ao ambiente escolar, principalmente no Ensino Médio, a argumentação é objeto de estudo frequente, pois, para obter uma boa avaliação na redação do ENEM, é preciso dominar algumas técnicas argumentativas. Entendemos, entretanto, que esse não pode ser seu maior objetivo. Conforme aponta Ducrot (apud KOCH, 1998, p. 29), a argumentatividade está inscrita na própria língua e, mesmo quando narramos ou descrevemos, em maior ou menor grau, fazemos uso de estratégias argumentativas.
} 


\title{
PERcursos Linguísticos • Vitória (ES) •v. 11 •n. 29 • 2021 • ISSN: 2236-2592 • Dossiê temático $\bullet O$ texto na pesquisa e no ensino: conhecimentos, práticas e desafios na contemporaneidade •
}

se percebe a veiculação de discursos de ódio e discriminação, com o intuito de rediscuti-los e rejeitá-los.

Bentes (2018, p.47), reconhece as dificuldades de implementação de práticas educativas que levem as pessoas a serem mais solidárias, tolerantes, sem, no entanto, perderem a capacidade crítica e de indignação com relação às injustiças sociais. Para a autora, entretanto, “o engajamento em uma atitude mais sistematicamente reflexiva e crítica sobre sua própria linguagem e a linguagem do outro é fortemente influenciado pela imersão dos sujeitos em práticas de linguagem que sejam significativas para eles". Por conta disso, Bentes afirma que:

\begin{abstract}
A meu ver, só é possível desenvolver as necessárias disciplinas do silêncio, da escuta atenta de outrem e da reflexão sobre o que o outro fala, se os temas a serem tratados forem envolventes, instigantes, polêmicos, de interesse público. Também não vamos desenvolver as necessárias disciplina e polidez nas interações se não formos imersos no universo no qual se forjam polêmicas e disputas de sentido a serem necessariamente resolvidas de forma cordial e racional. (BENTES, 2018, p 48).
\end{abstract}

A BNCC, em diálogo com os PCN, também destaca a necessidade de se pautar o ensino no apreço à diversidade: “(...) é preciso intensificar o desenvolvimento de habilidades que possibilitem o trato com o diverso e o debate de ideias. Tal desenvolvimento deve ser pautado pelo respeito, pela ética e pela rejeição aos discursos de ódio" (BRASIL, 2018, p.490). Promover a convivência (e não apenas a tolerância) com a diversidade de pensamentos, variedades linguísticas, crenças, dentre tantos outros aspectos antropológicos, é, sem dúvida, um dos grandes objetivos a serem alcançados pelo sistema educacional brasileiro e cabe a cada um dos atores inseridos nesse cenário oferecer a sua contribuição.

\section{A voz e a vez dos alunos}

Negreiros e Vilas Boas (2017, p. 118) apontam que, em geral, há “um significativo distanciamento entre as atividades escolares com a prática oral". Essa indiferença em relação à oralidade, entretanto, precisa ser rompida. Concordamos com Dolz e Schneuwly (2004, p. 64), os quais partem da hipótese de que é por meio das representações do gênero e pelo seu caráter integrador que as práticas de linguagem se materializam nas atividades de produção oral e escrita, constituindo-se uma fundamental ferramenta didática. Desse modo, a fim de nos aliarmos a essa premissa, propusemos o Argumentação e Oralidade, sobre o qual apresentaremos mais detalhes adiante. Tal projeto, destinado a trabalhar a oralidade formal por meio do gênero debate regrado, busca também coadunar-se com o que está exposto em Dolz, Schneuwly e Pietro (2004) e, para que pudesse ocorrer dentro das nossas possibilidades, 


\section{PERcursos Linguísticos • Vitória (ES) •v. $11 \bullet$ •n. 29 • 2021 • ISSN: 2236-2592 • Dossiê temático $\bullet O$ texto na pesquisa e no ensino: conhecimentos, práticas e desafios na contemporaneidade •}

elaboramos, inicialmente, a seguinte sequência didática, a qual discorre acerca das oficinas oferecidas aos alunos antes do primeiro debate ser realizado:

Quadro 1: Oficinas preparatórias para a participação nos debates

\begin{tabular}{|c|c|c|c|c|}
\hline OFICINAS & OBJETIVOS & ATIVIDADES & MATERIAL & DURAÇÃO \\
\hline $\begin{array}{l}\text { Apresentação } \\
\text { de um debate }\end{array}$ & $\begin{array}{l}\text { 1. Despertar o interesse } \\
\text { pelo gênero debate } \\
\text { regrado. } \\
\text { 2. Levar os alunos a } \\
\text { ouvir com atenção os } \\
\text { argumentos expostos por } \\
\text { cada debatedor. } \\
\text { 3. Demonstrar como se } \\
\text { dá a contra-argumen- } \\
\text { tação na modalidade } \\
\text { oral. }\end{array}$ & $\begin{array}{l}\text { Apresentação de } \\
\text { um debate } \\
\text { promovido por } \\
\text { universitários } \\
\text { pertencentes a } \\
\text { outras Socie- } \\
\text { dades de Deba- } \\
\text { tes do Rio de } \\
\text { Janeiro. }\end{array}$ & $\begin{array}{l}\text { 1.Pilot } e \\
\text { quadro (para } \\
\text { anotaro tema). } \\
\text { 2.Mesas e ca- } \\
\text { deiras para os } \\
\text { espectadores. } \\
\text { 3.Sineta para } \\
\text { controlar o } \\
\text { tempo de cada } \\
\text { debatedor. }\end{array}$ & $1 h 20 \mathrm{~min}$. \\
\hline $\begin{array}{l}\text { Módulo } 1 \text { : } \\
\text { Regras de cor- } \\
\text { tesia e o gê- } \\
\text { nero debate } \\
\text { regrado (parte } \\
\text { 1) }\end{array}$ & $\begin{array}{l}\text { 1.Destacar a impor- } \\
\text { tância de se manter a } \\
\text { cortesia, com a adoção } \\
\text { de palavras e expressões } \\
\text { que indiquem respeito } \\
\text { aos demais debatedores. } \\
\text { 2.Apresentar } \\
\begin{array}{l}\text { detalhes os papéis dos } \\
\text { primeiros auatro } \\
\text { debatedores. }\end{array}\end{array}$ & $\begin{array}{l}\text { Exposição oral } \\
\text { do professor } \\
\text { acerca do gêne- } \\
\text { ro debate re- } \\
\text { grado, suas } \\
\text { regras de corte- } \\
\text { sia e os papéis } \\
\text { pré-definidos } \\
\text { para os quatro } \\
\text { primeiros de- } \\
\text { batedores. }\end{array}$ & $\begin{array}{l}\text { 1.Pilot e qua- } \\
\text { dro. } \\
\text { 2.Documento } \\
\text { em vídeo com- } \\
\text { tendo a primei- } \\
\text { ra parte de um } \\
\text { debate regrado }\end{array}$ & $45 \mathrm{~min}$. \\
\hline $\begin{array}{l}\text { Módulo } 2 \text { : } \\
\text { Regras de cor- } \\
\text { tesia e o gê- } \\
\text { nero debate } \\
\text { regrado (parte } \\
\text { 2) }\end{array}$ & $\begin{array}{l}\text { 1.Levá-los a com- } \\
\text { preender a importância } \\
\text { de se respeitar a opinião } \\
\text { alheia e de saber ouvi-la } \\
\text { com respeito e tole- } \\
\text { rância. } \\
\text { 2. Apresentar em } \\
\text { detalhes os papéis dos } \\
\text { quatro últimos deba- } \\
\text { tedores. }\end{array}$ & $\begin{array}{l}\text { Reiteração oral } \\
\text { do professor } \\
\text { acerca da im- } \\
\text { portância de se } \\
\text { criar um am- } \\
\text { biente de cordia- } \\
\text { lidade e empa- } \\
\text { tia; os papéis } \\
\text { dos quatro últi- } \\
\text { mos debatedo- } \\
\text { res. }\end{array}$ & $\begin{array}{l}\text { 1.Pilot e qua- } \\
\text { dro. } \\
\text { 2.Documento } \\
\text { em vídeo com- } \\
\text { tendo a segun- } \\
\text { da parte de um } \\
\text { debate regra- } \\
\text { do. }\end{array}$ & $45 \mathrm{~min}$. \\
\hline
\end{tabular}

\footnotetext{
${ }^{4}$ Como o colégio em que está sendo desenvolvido o projeto fica na capital do Rio de Janeiro, torna-se mais fácil entrar em contato com universitários para apresentação ao vivo do debate. Outros professores, entretanto, sem essa possibilidade, podem acessar o link http://ibdebates.org/site/videos no qual encontrarão muitos vídeos de debates de altíssima qualidade, promovidos por universitários de todo o Brasil.
} 
PERcursos Linguísticos • Vitória (ES) •v. $11 \bullet$ n. 29 • 2021 • ISSN: 2236-2592 • Dossiê temático $\bullet O$ texto na pesquisa e no ensino: conhecimentos, práticas e desafios na contemporaneidade •

\begin{tabular}{|c|c|c|c|c|}
\hline $\begin{array}{lr}\text { Módulo } & 3^{5}: A \\
\text { fala } & \text { em } \\
\text { público } & \end{array}$ & $\begin{array}{l}\text { 1. Fazer com que os que } \\
\text { têm receio de falar em } \\
\text { público possam vencer a } \\
\text { timidez expressar a sua } \\
\text { opinião sobre um tema } \\
\text { da atualidade. }\end{array}$ & $\begin{array}{l}\text { Cada aluno tem } \\
\text { a oportunidade } \\
\text { de falar por até } \\
\text { dois minutos. }\end{array}$ & $\begin{array}{lll}\text { Mesa e ca- } \\
\text { deiras em } & \text { cír- } \\
\text { culo } & & \\
\end{array}$ & $1 h$ \\
\hline $\begin{array}{l}\text { Módulo 4: a } \\
\text { preparação } \\
\text { parao debate }\end{array}$ & $\begin{array}{l}\text { 1.Deliberar com os } \\
\text { alunos o tema do debate. } \\
\text { 2.Esclarecer a impor- } \\
\text { tância do estudo e do } \\
\text { planejamento do dis- } \\
\text { curso a ser proferido no } \\
\text { debate. }\end{array}$ & $\begin{array}{l}\text { 1.Levantamento } \\
\text { de temas do } \\
\text { interesse dos } \\
\text { alunos e rele- } \\
\text { vantes para a } \\
\text { sociedade. De } \\
\text { preferência, es- } \\
\text { ses assuntos } \\
\text { devem estar li- } \\
\text { gados aos di- } \\
\text { versos campos } \\
\text { de saberes a que } \\
\text { os alunos têm } \\
\text { acesso na esco- } \\
\text { la. } \\
2 . \quad \text { Exposição } \\
\text { oral do pro- } \\
\text { fessor acerca da } \\
\text { relevância de se } \\
\text { preparar para o } \\
\text { debate, por meio } \\
\text { da pesquisa, } \\
\text { atentando-se } \\
\text { para o fato de } \\
\text { que é necessário } \\
\text { estudar argu- } \\
\text { mentos favo- } \\
\text { ráveis e contrá- } \\
\text { rios ao tema. }\end{array}$ & $\begin{array}{l}\text { Pilot e quadro } \\
\text { para anotar os } \\
\text { temas suge- } \\
\text { ridos e promo- } \\
\text { ver a escolha } \\
\text { dos mais ade- } \\
\text { quados. }\end{array}$ & $30 \mathrm{~min}$. \\
\hline
\end{tabular}

A elaboração da sequência didática acima foi importante para que pudéssemos ter mais clareza quanto ao passo a passo necessário, a fim de que os alunos conhecessem o gênero escolhido como instrumento para aquisição e/ou aperfeiçoamento da oralidade formal. Concordamos com Carvalho e Ferrarezi Jr. (2018, p.31) ao afirmarem que o trabalho com a oralidade deva ocorrer em sala de aula, como um conteúdo programático. Entretanto, a definição do currículo e da carga horária de cada disciplina ainda não é feita isoladamente por cada professor. Infelizmente, as escolas ainda possuem programas que privilegiam excessivamente o ensino de gramática, quando o tempo gasto nessa tarefa poderia estar sendo

\footnotetext{
${ }^{5}$ Consideramos bastante produtiva a atividade de fala em público antes da realização do debate regrado. É uma excelente oportunidade para os alunos perderem a inibição e se acostumarem à fala que requer maior planejamento.
} 


\section{PERcursos Linguísticos • Vitória (ES) •v. 11 •n. 29 • 2021 • ISSN: 2236-2592 • Dossiê temático $\bullet O$ texto na pesquisa e no ensino: conhecimentos, práticas e desafios na contemporaneidade •}

investido na ampliação das competências de ler, escrever, ouvir e falar, conforme está exposto nos PCN (BRASIL, 1997, p.23). Além disso, nem todos os professores compartilham do entendimento de que o ensino dessas competências é de responsabilidade de todos os docentes e não apenas do professor de Português, conforme prevê os PCN (BRASIL, 1997, p.50). Assim, dentro da realidade da nossa escola, para que fosse possível seguir a sequência didática que elaboramos, de maneira sistemática e contínua, elaboramos, em 2017, o projeto Argumentação e Oralidade, com o intuito de que o trabalho com a oralidade não se restringisse a dias isolados ao longo do ano.

Até $2019^{6}$, o projeto contava com quatro alunos bolsistas de iniciação científica e três alunos voluntários. Esses alunos, ao lado da professora responsável, criaram a Sociedade de Debates do Colégio Pedro II. O papel dos discentes participantes é atuar diretamente na escolha dos temas, na divulgação do calendário de debates para os demais alunos da escola e no convite a palestrantes externos (em geral, universitários experientes também envolvidos com o movimento de debates). É importante destacar o protagonismo que se deseja atribuir aos estudantes, especialmente em relação à seleção dos temas. Concordamos com a BNCC quando afirma que é preciso "discutir sobre temáticas vinculadas a questões que os preocupam ou instigam sua curiosidade, privilegiando as que tiverem maior repercussão entre os estudantes" (BRASIL, 2018, p.501).

A participação como debatedor ou como ouvinte é voluntária e aberta a qualquer aluno do Ensino Médio, interessado em aprimorar a sua fala em público, e não está vinculada à atribuição de nenhum grau ou nota. De modo a atender os dois turnos em que a escola funciona, sem prejudicar as aulas regulares de outras disciplinas, foi escolhido o horário de $12 \mathrm{~h}$ às $13 \mathrm{~h}$ para a realização semanal dos debates. O cartaz a seguir foi elaborado e exposto nos corredores da escola, com o intuito de motivar a participação dos alunos:

Imagem 1: cartaz de divulgação do projeto

\footnotetext{
${ }^{6}$ Com a interrupção das aulas devido à pandemia, os alunos interessados continuaram ativos e mantendo contato por meio de um grupo de WhatsApp. Dadas as limitações, os debates passaram a ser mensais, em ambientes virtuais.
} 


\section{PERcursos Linguísticos • Vitória (ES) •v. 11 •n. 29 • 2021 • ISSN: 2236-2592 • Dossiê temático $\bullet O$ texto na pesquisa e no ensino: conhecimentos, práticas e desafios na contemporaneidade •}

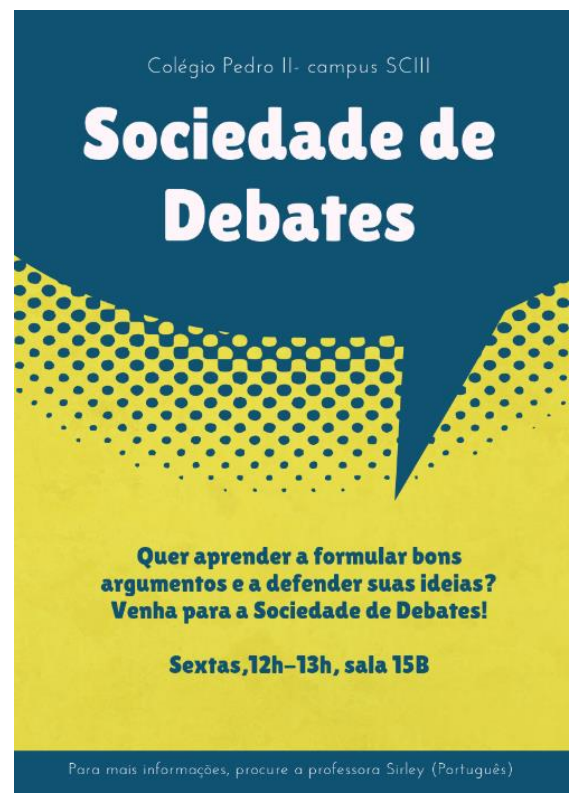

Fonte: arquivo pessoal da autora.

Uma Sociedade de Debates consiste em um grupo organizado de alunos debatedores e juízes e, geralmente, segue o padrão do Parlamento Britânico. Em tal modelo, há quatro duplas de debatedores que discutem a moção (recorte mais específico do tema escolhido) dada no dia do debate. Também no dia do evento, os debatedores descobrem se terão que argumentar favoravelmente à moção ou se deverão apresentar argumentos contrários a ela, de modo que duas duplas fiquem, portanto, a favor e duas duplas sejam contrárias, formando-se duas bancadas de duas duplas cada. $\mathrm{O}$ primeiro debatedor a proferir o seu discurso, pertence à bancada de defesa e o segundo, à bancada de oposição, de modo que as falas de defesa e oposição vão se alternando. Cada debatedor tem até sete minutos para apresentar seus argumentos.

A avaliação é feita por dois ou três avaliadores (em geral, a professora e dois alunos mais experientes) e julga a apresentação de argumentos acompanhados de referências, a oratória, a linha de raciocínio, a capacidade de responder as perguntas feitas e de refutar os argumentos da bancada oposta e, obviamente, de manter um comportamento no qual se revele respeito e cortesia pelos colegas debatedores. Ao final do debate, é declarado qual foi o melhor debatedor individual e qual foi a melhor dupla. Os avaliadores também precisam dar a todos os debatedores um "feedback" acerca do seu desempenho individual. Dada a facilidade de se gravar as falas por meio dos smartfones, a maioria dos debates foi gravada para composição de um corpus de pesquisa para a autora. Além disso, é encaminhado, por Whatsapp, o áudio do 


\section{PERcursos Linguísticos • Vitória (ES) •v. 11 •n. 29 • 2021 • ISSN: 2236-2592 • Dossiê temático $\bullet O$ texto na pesquisa e no ensino: conhecimentos, práticas e desafios na contemporaneidade •}

debate para que cada debatedor possa ouvir o seu próprio discurso e o dos colegas e, assim, melhorar cada vez mais as competências de ouvir e falar.

A BNCC reconhece a importância de se trabalhar com o gênero debate regrado. De acordo com o documento, é preciso: "Oportunizar a vivência de diferentes papéis em debates regrados (membro de uma equipe de debatedor, debatedor, apresentador/mediador, espectador - com ou sem direito a perguntas -, juiz/avaliador)" (BRASIL, 2018, p. 504). Além disso, nesse referencial, é destacada também a necessidade de se exercitar a escuta atenta, respeitando seu turno e tempo de fala, posicionando-se de forma fundamentada, respeitosa e ética diante da apresentação de propostas e defesas de opiniões, usando estratégias linguísticas típicas (como solicitar esclarecimento, detalhamento, fazer referência direta ou retomar a fala do outro, parafraseando-a para endossá-la, enfatizá-la ou enfraquecê-la), considerando propostas alternativas e reformulando seu posicionamento, quando for o caso, com vistas ao entendimento e ao bem comum.

Antes de passarmos às considerações finais, apresentaremos uma amostra ${ }^{7}$ da primeira metade de um debate cujo tema foi Eleições brasileiras e cuja moção foi Esta Casa repudia a existência de bancadas religiosas no Brasil. Conforme já dissemos, os alunos já sabiam qual seria o tema o debate, mas a moção (proposição a ser defendida ou contestada) souberam apenas com quinze minutos de antecedência. Também só no dia do debate, foi realizado um sorteio para saber quais debatedores se colocariam a favor da moção e quais seriam contrários a ela.

O objetivo de tais "regras", é o de levar os alunos a pesquisarem sobre o assunto, numa ação interdisciplinar. Nesse sentido, há o incentivo para sempre estarem dispostos a considerar a multiplicidade de posicionamentos que pode envolver uma questão e, assim, se colocarem no lugar do outro para compreender o seu ponto de vista. Afinal, nesse modelo de debate, podem, por meio de sorteio, acabar fazendo parte de uma bancada que defende algo bem diferente do que pensam.

A seguir, os estudantes, chamados de L1 e L3, advogam acerca da validade da moção, enquanto L2 e L4 discordam dela e tentam provar que é inadequada. Em outras palavras, a fim de convencer os juízes e a plateia, alternam-se discursos da defesa e de oposição. Para a transcrição das falas, preferimos não nos pautarmos pela língua escrita, justamente por ser outra

\footnotetext{
7 Informamos que todos os procedimentos foram realizados em conformidade com as normas institucionais e que foram atendidas as exigências da Resolução $n^{\circ}$ 510, de 7 de abril de 2016, referente a pesquisas envolvendo seres humanos.
} 


\section{PERcursos Linguísticos • Vitória (ES) •v. 11 •n. 29 • 2021 • ISSN: 2236-2592 • Dossiê temático $\bullet O$ texto na pesquisa e no ensino: conhecimentos, práticas e desafios na contemporaneidade •}

modalidade e ter características específicas, diferentes da modalidade oral. Optamos por seguir as normas que aparecem em Castilho \& Pretti (1986), as quais evidenciam os traços de planejamento on-line, típicos do discurso oral, como, por exemplo, hesitações, retomadas, falsas iniciações, etc.:

L1: boa tarde... eu sou a L. da 1303 e nós vamos repudiar a existência de bancadas religiosas em... em todos os campos políticos da nossa sociedade porque eles representam interesses ideológicos que vãofazer parte pra toda população eh ... sendo que eles deveriam representar a todos... tanto que eh... um exemplo que nós temos é a criminalização da homofobia que eh... por conta de ser a maior parte... eh... o congresso negligenciou... e ficou pro STF que não é algo para eles... e... mesmo que eles tenham sido eleitos pela maior parte... eles não representam todos... então eles não tinham que levar a ideologia deles... como uma forma de... como uma forma de...como uma forma de julgar ou tentar mandar no Brasil (...)

L2: boa tarde gente... eu sou o D. e... mais o quê?... só isso mesmo... a:: a gente acha necessário a questão de haver bancadas religiosas pro nosso governo por... por razões culturais muito evidentes... no nosso caso especificamente aqui no Brasil... uma coisa que é bastante interessante é a importância da diversidade... então como aqui a gente tá falando de bancadas... mais do que apenas a predominância uma religião associada ao ao estado... a gente precisa de uma representatividade diversificada porque::... a nossa composição ela também foi diversificada então a religião ela de certa forma atenderia desde... sei lá... cristãos eh... religiões mais africanas e até mesmo alguns cultos à divindades indígenas também (...)

Para além das características inerentes ao texto falado, evidentes nas amostras de L1 e L2, gostaríamos de destacar o fato de os alunos colocarem em prática as orientações acerca do que seria protocolar em uma fala nesse tipo de gênero: cumprimentam os ouvintes, se apresentam, demonstram respeito pelos colegas e empregam vocabulário adequado ao contexto.

Como a participação no projeto é voluntária e aberta a qualquer aluno interessado, constantemente, temos novos estudantes ingressando. Muitos desses alunos, inicialmente muito tímidos, querem apenas assistir aos debates. Com o tempo, ganham mais confiança e, incentivados pelos próprios colegas e pela professora, começam a debater também. L2, por exemplo, participava pela primeira vez do debate e, embora tenha demonstrado alguma insegurança logo na apresentação: “eu sou o D. e... mais o quê?... só isso mesmo...”, acaba se saindo muito bem, inclusive no argumento apresentado, já que destaca o apreço pela diversidade, a qual se estenderia a diferentes bancadas religiosas (cristã, de matriz africana ou 


\section{PERcursos Linguísticos • Vitória (ES) •v. 11 •n. 29 • 2021 • ISSN: 2236-2592 • Dossiê temático $\bullet O$ texto na pesquisa e no ensino: conhecimentos, práticas e desafios na contemporaneidade •}

indígena). De modo análogo, L1 também consegue deixar claro seu ponto de vista e argumenta que a existência de bancadas religiosas atrapalharia a promulgação de leis importantes para toda a sociedade, como a relacionada à homofobia.

As falas de L3 e L4, a seguir, são de alunos mais experientes. Ambos se apresentam de maneira mais completa, fazendo referência inclusive ao nome do Colégio, pois já estavam acostumados, inclusive, a debaterem em campeonatos com alunos universitários. Essa experiência acumulada é perceptível na retomada da fala da dupla, como faz L3: “completando o que a minha dupla trouxe", com o intuito de ampliar a argumentação feita anteriormente por L1.

L3: olá... boa tarde... eu me chamo L... eu faço parte da Sociedade de Debates do Colégio Pedro II... sou da turma 1203 e hoje eu vim aqui defender por que que nós repudiamos a existência de bancadas religiosas... em primeiro lugar eh:.... fazendo..... completando o que a minha dupla trouxe... eh: as bancadas religiosas elas defendem interesses ideológicos de religiões específicas... isso não é benéfico porque... porque elas não visam eh:: elas visam à criação das leis a aprovação das leis baseado no que seria benéfico para a população e sim para o que seria benéfico para o grupo específico que elas representam... um exemplo disso que ela trouxe a homofobia que foi negligenciada por muito tempo... eh:.: no Congresso... não criaram leis até criavam mas eles não aprovavam porque o Congresso composto por muitos deputados conservadores eh: de bancadas religiosas eles não aprovavam porque isso não representava a ideologia religiosa deles (...)

L4: boa tarde a todos... meu nome é G. P. e eu sou aluno do magnífico Colégio Pedro II... o lendário Colégio previsto na Constituição Federal de 1988...eh:: agradeço a presença da bancada de defesa... a sensatíssima bancada de oposição e também a mesa avaliadora... eh: senhoras e senhores eu começo trazendo o meu primeiro argumento que é justamente que a defesa dos interesses eh: da instituições religiosas... das bancadas religiosas... das pessoas eh:: que contém a sua religião dentro da política é extremamente importante e também extremamente eh:: lícito e previsto pela Constituição Federal... então senhoras e senhores esse é primeiro ponto que vim trazer pra mostrar pra vocês que repudiar a existência de repudiar a existência de bancadas religiosas é uma coisa ridícula... é uma coisa que não faz sentido nenhum quando é proposta pela bancada de defesa nesta manhã eh::: exatamente porque nós conhecemos uma expressão chamada lugar de fala que embora seja uma expressão que diversas 


\section{PERcursos Linguísticos • Vitória (ES) •v. 11 •n. 29 • 2021 • ISSN: 2236-2592 • Dossiê temático $\bullet O$ texto na pesquisa e no ensino: conhecimentos, práticas e desafios na contemporaneidade •}

vezes pode parecer contraditória tem o seu sentido sim... o que diz a ideia do lugar de fala? ela nos mostra por exemplo que quando uma pessoa ela vive aquilo que ela está dizendo... ela tem muito mais eh:.: ela tem muito mais autoridade sobre o que ela está falando (...)

A fala de L4 revela, como dissemos, mais intimidade com o gênero trabalhado. $\mathrm{O}$ estudante, além de se apresentar, também agradece à bancada de defesa e à bancada de oposição, caracterizada como "sensatíssima", da qual ele mesmo faz parte. A escolha do superlativo para qualificar a sua própria bancada, obviamente, não foi ao acaso, mas com uma clara intenção argumentativa. Também se percebe esse mesmo propósito quando se refere à moção como algo ridículo e que não faz sentido nenhum.

Nota-se ainda que, nesse primeiro minuto de fala, L4 apresenta dois argumentos que sustentam o seu posicionamento, que são: a) o fato de a Constituição garantir a existência de tais bancadas ("lícito e previsto pela Constituição Federal”) e b) a composição dessas bancadas ser justificável justamente por seus parlamentares serem pessoas ligadas à religião, o que conferiria a elas mais legitimidade em suas questões, pois estariam subsidiadas pelo que se chama de lugar de fala, expressão muito usada por ativistas ao se dar voz a pessoas que vivenciam determinada problemática.

Essa experiência acumulada por L3 e L4 nos prova o quanto é importante um trabalho recorrente com a oralidade formal e que, se é verdade que só se aprende a escrever, escrevendo, também é comprovado que só se aprende a fazer discursos orais, pondo isso em prática. A possibilidade de se ir além do falar cotidiano, restrito a indivíduos do núcleo familiar ou com os quais se tem intimidade, precisa ser uma meta a ser alcançada por toda comunidade escolar, portanto.

\section{Considerações finais}

Ao longo do texto, buscamos mostrar que as mudanças desejadas no ensino de Língua Portuguesa passam, sem desconsiderar outros fatores, pelo incremento do trabalho com gêneros orais, a fim de que aqueles que demandam maior formalidade tornem-se objeto de ensino.

A escolha do gênero debate regrado atendeu às nossas expectativas quanto ao desenvolvimento da fala em público e da elaboração de argumentos pertinentes, tão necessários em nossa sociedade. Entretanto, tão relevante quanto essas habilidades mencionadas é o 


\section{PERcursos Linguísticos • Vitória (ES) •v. 11 •n. 29 • 2021 • ISSN: 2236-2592 • Dossiê temático $\bullet O$ texto na pesquisa e no ensino: conhecimentos, práticas e desafios na contemporaneidade •}

respeito às regras de cortesia, a fim de que a discussão sempre fique restrita ao campo das ideias. Se almejamos uma sociedade melhor, isso passa pela assimilação do conceito de empatia e pela adoção de condutas condizentes com a civilidade.

Gostaríamos ainda de reafirmar nosso posicionamento de que é a partir da própria prática que são criadas e desenvolvidas as habilidades exigidas para a sustentação de ideias e, com o exercício constante, os educandos podem se tornar cada vez mais capazes de defenderem seus posicionamentos também na modalidade oral da língua. Desse modo, com esse entendimento de que se aprende a debater através da participação em debates e de que a modalidade oral da língua também deve ser um alvo da escola, é que reforçamos a importância de se oferecer cada vez mais oportunidades aos discentes de aprenderem através da experiência e, dessa maneira, paulatinamente, se tornarem mais confiantes e seguros ao assumirem a palavra em quaisquer contextos situacionais nos quais estiverem inseridos.

Nosso interesse é, portanto, pela formação de sujeitos cada vez mais autônomos, capazes de alçarem a sua voz em defesa de seus direitos a fim de que estes não sejam suprimidos ou concedidos em parte. Assim, as discussões aqui levantadas corroboram a necessidade de que as produções acadêmico-científicas cheguem aos professores da Educação Básica, de modo que haja uma constante interlocução entre os pesquisadores universitários das áreas de Educação e de Letras e aqueles responsáveis pela implementação das pesquisas.

\section{Referências}

ALMEIDA, Milton José de. Ensinar Português? In: GERALDI, João Wanderlei (org.). O texto na sala de aula. 4. ed. São Paulo: Ática, 2006.

BENTES, Anna Christina. Oralidade, política e direitos humanos. In: ELIAS, Vanda Maria (org.). Ensino de Língua Portuguesa: oralidade, escrita, leitura. 1.ed. São Paulo: Contexto, 2018.

BRASIL. MEC. Secretaria de Educação Fundamental. Parâmetros curriculares nacionais: Língua Portuguesa/ Secretaria de Educação Fundamental. Brasília. 1997.

BRASIL. Ministério da Educação. Base Nacional Comum Curricular. Brasília, 2018.

BROWN, Penelope; LEVINSON, Stephen. Politeness. Cambridge Univ.Press, 1987. 


\section{PERcursos Linguísticos • Vitória (ES) •v. 11 •n. 29 • 2021 • ISSN: 2236-2592 • Dossiê temático $\bullet O$ texto na pesquisa e no ensino: conhecimentos, práticas e desafios na contemporaneidade •}

CARVALHO, Robson Santos de; FERRAREZI Jr., Celso. Oralidade na Educação Básica: o que saber, como ensinar. 1.ed. São Paulo: Parábola, 2018.

CASTILHO, Ataliba Teixeira de; PRETI, Dino. (orgs.). A linguagem falada culta na cidade de São Paulo: materiais para seu estudo. 1.ed. São Paulo: T. A. Queiroz, 1986.

CASTILHO, Ataliba Teixeira de. A língua falada no ensino de Português. 1.ed. São Paulo: Contexto, 1998.

CASTILHO, Ataliba Teixeira de; BASILIO, Margarida. (org.) Gramática do Português falado. 1.ed. Campinas: Editora da UNICAMP/FAPESP, vol. IV, 1996.

CHARAUDEAU, Patrick. A argumentação talvez não seja o que parece ser. In.: GIERING, M. E.; TEIXEIRA, M. Investigando a linguagem em uso: estudos em linguística aplicada. São Leopoldo: Ed. Unisinos, 2004. p. 33-44.

COSTA-MACIEL, Débora Amorim Gomes da; BILRO, Fabrini Katrine da Silva. O que é ensinar a oralidade? Análise das proposições didáticas apresentadas em livros destinados aos anos iniciais da Educação Básica. Educação em revista, Belo Horizonte, v.34, p. 1-29, 2018.

DOLZ, Joaquim; SCHNEUWLY, Bernard. Gêneros e progressão em expressão oral e escrita elementos para reflexões sobre uma experiência suíça (francófona). In: SCHNEUWLY, Bernard e DOLZ, Joaquim. Gêneros orais e escritos na escola. Traduzido por Roxane Rojo e Glaís Sales Cordeiro. 1.ed. Campinas, SP: Mercado das Letras, 2004, p. 35-60.

DOLZ, Joaquim, NOVERRAZ, Michèle; SCHNEUWLY, Bernard. Sequências didáticas para o oral e a escrita: apresentação de um procedimento. In: SCHNEUWLY, Bernard e DOLZ, Joaquim. Gêneros orais e escritos na escola. Traduzido por Roxane Rojo e Glaís Sales Cordeiro. 1.ed. Campinas, SP: Mercado das Letras, 2004, p. 213-239.

FÁVERO, Leonor Lopes et al. Oralidade e escrita: perspectivas para o ensino de língua materna. 5. ed. São Paulo: Cortez, 2005. 


\section{PERcursos Linguísticos • Vitória (ES) •v. 11 •n. 29 • 2021 • ISSN: 2236-2592 • Dossiê \\ temático $\bullet O$ texto na pesquisa e no ensino: conhecimentos, práticas e desafios na contemporaneidade •}

FERRAREZI, Celso. Pedagogia do silenciamento: a escola brasileira e o ensino de língua materna. 1.ed. São Paulo: Parábola Editorial, 2014.

GOMES-SANTOS, S.N. Modos de apropriação; do gênero debate regrado na escola: uma abordagem aplicada. Delta, v.25, p. 39-66, 2009.

KOCH, Ingedore Villaça. (org.) Gramática do Português falado. 1.ed. Campinas: Editora da UNICAMP/FAPESP, vol. vi, 1996.

KOCH, Ingedore Villaça. A inter-ação pela linguagem. 4ª ed. São Paulo: Cortez, 1998.

KOCH, Ingedore Villaça. Desvendando os segredos do texto. São Paulo: Cortez, 2002.

$\mathrm{KOCH}$, Ingedore Villaça \& ELIAS, Vanda Maria. Fala e escrita. In: KOCH, Ingedore Villaça: Ler e escrever: estratégias de produção textual. 1.ed. São Paulo: Contexto, 2012.

LEAL, Telma Ferraz; GOIS, Sianne (Orgs.). A oralidade na escola: a investigação do trabalho docente como foco de reflexão. Belo Horizonte: Autêntica, 2012.

MAGALHÃES, Tânia Guedes. Oralidade na sala de aula: alguém "fala" sobre isso?. Instrumento. n.7, p. 65-81, 2006.

MARCUSCHI, Luiz Antônio. Análise da conversação. 1.ed. São Paulo: Ática, 1986.

MARCUSCHI, Luiz Antônio. Da fala para a escrita: atividades de retextualização. São Paulo: Cortez, 2001.

NEGREIROS, Gil; VILAS BOAS, Gislaine. A oralidade na escola: um (longo) percurso a ser trilhado. Letras, v.27, n.54, p. 115-126, jan./jun.2017.

NONATO, Sandoval. Processos de legitimação da linguagem oral no ensino de Língua Portuguesa: panorama histórico e desafios atuais. Cadernos Cedes. v. 38, n. 105, p. 222-239, maio-ago.2018.

SCHNEUWLY, Bernard. Palavra e ficcionalização: um caminho para o ensino da linguagem oral. In: SCHNEUWLY, Bernard e DOLZ, Joaquim. Gêneros orais e escritos na escola. Traduzido por Roxane Rojo e Glaís Sales Cordeiro. 1.ed. Campinas, SP: Mercado das Letras, 2004, p. 109-124.

SCHNEUWLY, Bernard; DOLZ, Joaquim. Gêneros orais e escritos na escola. Traduzido por Roxane Rojo e Glaís Sales Cordeiro. 1.ed. Campinas, SP: Mercado das Letras, 2004. 